CEP Discussion Paper No 672

January 2005

\title{
Multinationals and US Productivity Leadership: \\ Evidence from Great Britain
}

Chiara Criscuolo and Ralf Martin

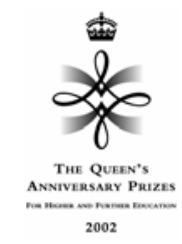




\begin{abstract}
We study the productivity of US owned plants in the UK. Using a new dataset that identifies foreign and domestic MNEs, we find that UK MNEs are less productive than US affiliates, but as productive as non US foreign affiliates. We investigate the source of the US and MNE advantage. We find evidence confirming that the MNE advantage is driven by sharing superior firm level assets across plants and by cherry picking the better plants in a country. The additional superiority of US firms seems entirely driven by their particular ability to takeover the best British plants. Thirdly, the study features a novel approach to TFP calculation.
\end{abstract}

JEL Classification: F230, L600

Keywords: Multinational Firms, Productivity, Foreign Ownership, US leadership, Double FixedEffects

This paper was produced as part of the Centre's Productivity and Innovation Programme. The Centre for Economic Performance is financed by the Economic and Social Research Council.

\title{
Acknowledgements
}

This work contains statistical data from the Office of National Statistics (ONS) which is Crown copyright and reproduced with the permission of the controller of HMSO and Queens Printer for Scotland. The use of the ONS statistical data in this work does not imply the endorsement of the ONS in relation to the interpretation or analysis of the statistical data.

For extremely helpful comments we thank Lee Branstetter, Richard Disney, Jonathan Haskel, Wolf- gang Keller, John Haltiwanger, Steve Nickell, Nick Oulton, Steve Redding, John Van Reenen, Prabhat Vaze and participants to the 2004 NBER Summer Institute. This research has been produced under contract with the ONS. We gratefully acknowledge financial support from the Evidence-Based Policy Fund and from the ESRC/EPSRC Advanced Institute of Management Research, grant number RES-331-25-0030. Errors and opinions are those of the authors alone.

Chiara Criscuolo is a Researcher at University College London (UCL) and at the Centre for Research into Business Activity (CeRiBA).Email: c.criscuolo@ucl.ac.uk

Ralf Martin is an Occasional Research Assistant at the Centre for Economic Performance(CEP), London School of Economics(LSE) and also a Researcher at the Centre for Research into Business Activity (CeRiBA). Email: r.martin@1se.ac.uk

Published by

Centre for Economic Performance

London School of Economics and Political Science

Houghton Street

London WC2A $2 \mathrm{AE}$

All rights reserved. No part of this publication may be reproduced, stored in a retrieval system or transmitted in any form or by any means without the prior permission in writing of the publisher nor be issued to the public or circulated in any form other than that in which it is published.

Requests for permission to reproduce any article or part of the Working Paper should be sent to the editor at the above address.

(C) C. Criscuolo and R. Martin, submitted 2005

ISBN 0753018128 


\section{Introduction}

International comparisons show that the US is the world's most productive economy ${ }^{1}$ and much research has gone into understanding the determinants of this productivity leadership. There are two broad categories of factors that could be responsible for this success: on the one hand the business environment and on the other firm or plant specific factors. The business environment comprises the quality of a country's workforce, the efficiency of public infrastructure as well as geographical advantages. Firm and plant specific factors include more efficient production processes and management techniques, better marketing or more valuable patents or brands. Plant level studies of business units located in the same country but owned by firms of different nationalities can potentially distinguish between these two hypotheses. Since the business environment is the same for all plants in the sample, any observed productivity differences are due to differences in plant or firm specific factors.

When examining foreign ownership effects such as the suggested US advantage in plant level datasets we have to be careful in choosing our comparison group. For various countries - including the US - researchers ${ }^{2}$ have found that foreign owned firms are on average more productive than domestic ones. However, since foreign owned plants are by definition part of a multinational enterprise (MNE) whereas only a small fraction of domestic firms are multinational, this might reflect a general MNE advantage rather than country specific advantages. Several theoretical studies (see for example Dunning (1981); Helpman (1984); Markusen (1995)), suggest that factors such as language barriers and ignorance of local business networks give foreign firms a disadvantage. Thus, since setting up abroad is likely to be more expensive than setting up at home, if MNE firms nevertheless manage to stay in business, they must have superior firm specific assets such as better management techniques and better production technology - that they can share with their affiliates. ${ }^{3}$

Therefore, in order to compare like with like we need to compare US MNEs with

\footnotetext{
${ }^{1}$ see for example O'Mahony and de Boer (2002).

${ }^{2}$ For the UK: Griffith (1999), Griffith and Simpson (2001), Oulton (2000) and Harris (1999) using the ARD; Conyon et al. (2002) using firm level data; Davies and Lyons (1991) using industry level data. The study by Doms and Jensen (1998) for the US. Lipsey and Sjoholm (2002) document higher wages paid by foreign-owned firms in Indonesia.

${ }^{3}$ We concentrate here on testing the "Ownership" hypothesis of the Dunning's Ownership Location Internalisation framework.
} 
other - domestic and foreign - MNEs. While foreign ownership identifiers are commonly included in plant level productivity datasets, data that would allow the identification of domestic MNEs has been scarce. Doms and Jensen (1998) is the first US study that controls for the multinationality of domestic firms. They find that, among multinationals, plants owned by US MNEs are the productivity leaders in the US, whereas domestic non MNE plants lag far behind MNEs owned units.

Using a newly available dataset - the Annual Inquiry into Foreign Direct Investment (AFDI) - we are, for the first time, able to identify domestic MNEs in a large scale UK plant level productivity dataset. This allows us to make several contributions to the existing literature. Firstly, our study qualifies the findings of Doms and Jensen in one important respect: in their study they cannot rule out that the leadership of US MNE owned plants is the consequence of a home advantage rather than of intrinsic transferable firm level advantages. The first innovation of this paper, therefore, is to establish the leadership of US MNEs in Britain, which shows that the US MNE advantage found by Doms and Jensen is not a home advantage. Secondly, we confirm with British data that the foreign ownership advantage is indeed by and large an MNE advantage. Finally, we attempt to explain the nature of the US and MNE advantage further using the longitudinal dimension of our data. We examine two questions. First, are the drivers of the MNE and the US advantage firm or plant specific? This distinction is important because the Dunning account, and many theories involving MNEs (see for example Markusen (1995) and Helpman (1984)), assume a firm specific advantage that multinational enterprises can share among plants. An alternative explanation is that the MNE productivity advantage is driven by an ability of MNEs to takeover plants which themselves have superior productivity even before the takeover. We find that the MNE advantage consists of both firm and plant effects. On the other hand, the additional US advantage seems to be primarily driven by plant effects. US MNEs take over plants that are about 10 percent more productive than plants taken over by other MNEs.

We also examine if there is evidence for a causal relationship from foreign engagement of a firm to the productivity of its plants in the home market. ${ }^{4}$ This would be in line with technology sourcing or other learning effects (see for example Branstetter (2001) and for a review Keller (2004)). To identify such effects we look at UK firms that start investing

\footnotetext{
${ }^{4}$ Dunning's theory would suggest a causal relation from superior productivity to foreign direct investment.
} 
abroad - i.e. become multinational - during our sample period. However, we do not find any significant evidence for such an effect.

The rest of the paper is organised as follows: in sections 2 and 3 we describe our dataset. Section 4 shows that US owned plants are the productivity leaders in the UK, both in terms of labour productivity and in terms of total factor productivity (TFP), and that only part of the US ownership advantage can be explained by a multinational effect. In section 5 we show that this result is robust to alternative classifications of the foreign group and to different specifications of the production function. In particular, we show the robustness of our results when we control for the endogeneity of inputs and account for imperfect competition using an approach on the lines of Olley and Pakes (1996) and Levinsohn and Petrin (2000). In section 6 we disentangle the US productivity effect using a two-step estimation procedure. Section 7 concludes.

\section{Data Sources}

Our sample is drawn from the Annual Respondents Database (ARD) ${ }^{5}$ which is the UK equivalent of the US Longitudinal Respondents Database (LRD). It is a dataset made available by the Office for National Statistics (ONS) based on information from the mandatory annual survey of UK businesses, called Annual Business Inquiry (ABI) ${ }^{6}$ The ARD unit of observation is defined by the ONS as an 'autonomous business unit'. We refer to this level of observation as a 'plant'. ${ }^{7}$ It is important to note that the ARD does not consist of the complete population of all UK businesses. All businesses with more than 100 employees $^{8}$ are sampled, but smaller businesses are sampled randomly. Only data on British plants - i.e. excluding Northern Ireland - was made available to us. Each year the sampled plants account for around $90 \%$ of total UK manufacturing employment. ${ }^{9}$ In sum, our sample is an unbalanced panel of about 19,000 manufacturing plants which we

\footnotetext{
${ }^{5}$ More extensive descriptions of the ARD can be found in Criscuolo, Haskel and Martin (2003), Griffith (1999) and Oulton (1997)

${ }^{6}$ Annual Census of Production until 1998.

${ }^{7}$ Some of these business units are spread across several sites and are therefore not plants in the strict sense of the word. In about 80 percent of all cases a business unit is located entirely at a single mailing address.

${ }^{8}$ In some years the threshold was 250 employees, for details we refer to Criscuolo, Haskel and Martin (2003).

${ }^{9}$ To examine if our results are sensitive to the oversampling of larger plants we run regressions with inverse sampling probabilities as weights. These results, available upon request from the authors, are not qualitatively different from the unweighted results reported in the next section.
} 
observe annually for the years from 1996 to 2000.

The country of ownership of a foreign firm operating in the UK - and thus the ability to identify foreign owned MNE plants in the UK - is provided in the ARD. ${ }^{10}$ While this identifies foreign owned plants, until now it has not been possible to identify UK MNEs. To do this we use the Annual Foreign Direct Investment (AFDI) register.

The AFDI is an annual survey of businesses which requests a detailed breakdown of the financial flows between UK firms and their overseas parents or subsidiaries. The AFDI is thus a survey run at the firm and not at the plant level. The AFDI register provides the sampling frame of the AFDI and contains the population of all UK firms which are engaging in or receiving foreign direct investment (FDI). The working definition of FDI for this purpose is that the investment must give the investing firm a 'significant' amount of control over the recipient firm. The ONS considers this to be the case if the investment gives the investor a share of at least 10 percent of the recipient firm's capital.

To conduct the AFDI, the ONS maintains a register which holds information on the country of ownership of each foreign firm and on which UK firms have foreign subsidiaries or branches. ${ }^{11}$ This register is designed to capture the universe of firms that are involved in foreign direct investment abroad and in the UK. We consequently define as 'multinational' each plant in the ARD that is owned by a firm which appears in the AFDI register. ${ }^{12}$

A problem with the AFDI register is that information is not always up-to-date. If a firm engages or receives FDI, it will only be included in the AFDI register after the ONS learns from various sources, including commercial data and newspapers, that this happened. Consequently, the register population has varied spuriously over the years with the ONS' success in identifying such firms. However, we believe that this problem does not weaken the conclusions that can be drawn from our results. If some of the plants

\footnotetext{
${ }^{10}$ The ARD data is supplemented here with information from Dun\&Bradstreet global "Who Owns Whom" database. According to Dun\&Bradstreet, the nationality of a plant is determined by the country of residence of the global ultimate parent, i.e. is the topmost company of a world-wide hierarchical relationship identified bottom-to-top using any company which owns more than $50 \%$ of the control (voting stock, ownership shares) of another business entity.

${ }^{11}$ The ONS distinguishes between subsidiaries and branches as follows: a 'subsidiary' is a company where the parent company holds more than $50 \%$ of the equity share capital; a 'branch' is a permanent establishment as defined for UK corporation tax and double taxation relief purposes; companies where the investing company holds between $10 \%$ and $50 \%$ of the equity share capital, i.e. does not have a controlling interest but participates in the management, are defined as 'associates'. The country of ownership is identified using the nationality of the immediate owner, Office for National Statistics (2002) p.120.

${ }^{12}$ Details of the procedure followed to merge the AFDI and the ARD are reported in Criscuolo and Martin (2003).
} 
Table 1: Importance of MNE

(Average numbers and shares 1996-2000)

\begin{tabular}{|c|c|c|c|c|c|c|c|c|}
\hline & \multicolumn{2}{|c|}{ number of plants } & \multicolumn{2}{|c|}{ shares } & \multicolumn{2}{|c|}{ emp share } & \multicolumn{2}{|c|}{ va share } \\
\hline & (1) & (2) & $(3)$ & (4) & $(5)$ & $(6)$ & $(7)$ & (8) \\
\hline & pop. & sample & pop. & sample & pop. & sample & wghtd & unwghtd \\
\hline GB Non MNE & 158,868 & 8,394 & 0.96 & 0.75 & 0.59 & 0.41 & 0.44 & 0.31 \\
\hline GB MNE & 3,062 & 1,427 & 0.02 & 0.13 & 0.21 & 0.29 & 0.27 & 0.32 \\
\hline US & 1,172 & 615 & 0.01 & 0.05 & 0.10 & 0.14 & 0.15 & 0.19 \\
\hline FOR & 1,708 & 825 & 0.01 & 0.07 & 0.11 & 0.16 & 0.14 & 0.18 \\
\hline
\end{tabular}

Notes: Figures reported are annual averages. Population refers to all businesses in the register, sample refers to businesses in the ARD (all large plants plus a sample of smaller plants). Column 5 uses employment information from administrative data for non-surveyed plants. Column 7 and 8 use value added at factor cost. Column 7 weights surveyed observations using employment weights calculated as described in Appendix A to yield statistics representative of the whole population. GB non $M N E$ denotes domestic plants with no FDI; $G B M N E$ is one for all domestic multinationals; $U S$ is one for all plants owned by a US multinational and FOR is one for all plants owned by non US foreign multinationals.

Source: Authors' calculations using matched ARD-AFDI data over the 1996-2000 period.

which we record as non-multinational are actually multinational plants and we still find that multinationals are more productive than non-multinational plants then this means that this result would be even stronger if we measured the status of all plants correctly.

\section{Descriptive Statistics}

Table 1 shows the number of multinational plants that we can identify in the population and in the sample and their relevance in terms of employment and value added. Column 1 reports the number of domestic plants with no FDI, (defined as GB Non MNEs), British MNEs (GB MNE), US MNEs (US) and non US foreign owned plants (FOR) in the whole population. Column 2 shows the number of plants in each group for the sample of plants surveyed by the ONS to compile the ARD. Columns 3 and 4 translate these numbers into shares. Column 3 shows that 1 percent of all plants in Britain are US owned, almost as much as all other foreign owned plants combined. Indeed, US MNEs represent more than 40 percent of all foreign owned plants in Britain $((615+825) / 825)$. Similar figures hold for the share in employment (column 5) and value added (column 7), where US owned plants represent 47 and 51 percent of FDI, respectively. These figures are consistent with the fact that the most productive companies are also likely to have the highest market share. Also, since US MNEs are on average larger, the relative share of US MNEs in the selected sample is much higher: whereas in the total population US MNEs take a share of about 1 percent, in the sample the same figure rises to 5 percent.

Table 2 reports averages and standard deviations for relevant variables. Panel 1 shows 
Table 2: Summary Statistics in the 1996-2000 pooled sample

\begin{tabular}{|c|c|c|c|c|c|}
\hline & & GB non MNE & GB MNE & US & FOR \\
\hline \multirow[t]{2}{*}{1} & VA/Emp & 27.96 & 36.87 & 46.57 & 43.10 \\
\hline & & $(183.47)$ & $(39.30)$ & $(80.79)$ & (51.43) \\
\hline \multirow[t]{2}{*}{2} & GO/Emp & 76.55 & 105.35 & 146.23 & 156.39 \\
\hline & & $(207.92)$ & $(132.22)$ & $(232.02)$ & $(283.73)$ \\
\hline \multirow[t]{2}{*}{3} & Mat/Emp & 50.54 & 69.78 & 99.16 & 114.43 \\
\hline & & (85.04) & $(85.91)$ & (163.67) & $(221.25)$ \\
\hline \multirow[t]{2}{*}{4} & $\mathrm{~K} / \mathrm{Emp}$ & 38.23 & 65.43 & 85.54 & 108.92 \\
\hline & & $(92.78)$ & $(73.07)$ & $(125.61)$ & $(366.37)$ \\
\hline \multirow[t]{2}{*}{5} & Employment & 142.15 & 475.02 & 537.00 & 445.62 \\
\hline & & $(264.51)$ & $(954.81)$ & (1394.88) & (1134.80) \\
\hline \multirow[t]{2}{*}{6} & AverageWage & 17.25 & 21.35 & 24.13 & 23.40 \\
\hline & & $(7.89)$ & (10.13) & $(8.53)$ & $(8.21)$ \\
\hline \multirow[t]{2}{*}{7} & VA/Sales & 0.43 & 0.40 & 0.38 & 0.33 \\
\hline & & $(0.17)$ & $(0.15)$ & $(0.15)$ & $(0.15)$ \\
\hline
\end{tabular}

Notes: Figures are unweighted averages over the sample period. Standard deviations in parenthesis. Figures in panels 1 to 4 and 6 are in thousands of pounds. Figures in panel 5 are head counts. The number of observations in all panels is 38,501. GB non MNE denotes domestic plants with no FDI; GB MNE is one for all domestic multinationals; $U S$ is one for all plants owned by a US multinational and FOR is one for all plants owned by non US foreign multinationals.

Source: Authors' calculations using matched ARD-AFDI data over the 1996-2000 period.

the US owned plants' labour productivity lead: averaging over the whole manufacturing sector and not controlling for industry we find that plants owned by US firms have an advantage of 26 percent $((46.57$ - 36.87)/36.87) over British MNEs and an advantage of 8 percent $((46.57-43.10) / 43.10)$ over other foreign MNEs. In terms of gross output per employee (panel 2) the ranking changes: foreign non-US owned plants are the most productive and in general the foreign advantage becomes more dramatic. Panels 3 and 4 suggest that the figures in panel 2 can be partly explained by the fact that non US foreign owned plants have much higher material-to-labour and capital-to-labour ratios than all other plants. Panel 5 shows that US plants are on average larger and pay higher wages. This might imply that at least part of the US advantage is the consequence of scale effects $^{13}$ and employment of higher skilled workers. Thus, the US advantage might not be due to technological or managerial superiority but simply to different input choices.

\footnotetext{
${ }^{13}$ Here we refer to scale effects at the plant level. In our study we cannot control for the scale of the global operations of MNEs, e.g. we do not have information on 'global employment'.
} 
Table 3: Relative productivity of MNE

(estimates of Equation 2)

\begin{tabular}{|c|c|c|c|c|c|}
\hline dep. var & (1) & (2) & (3) & $\begin{array}{c}(4) \\
\ln \frac{G O}{L} \\
\end{array}$ & (5) \\
\hline \multirow{2}{*}{ US } & 0.349 & 0.144 & 0.076 & 0.045 & 0.044 \\
\hline & $(0.018)^{* * *}$ & $(0.022)^{* * *}$ & $(0.007)^{* * *}$ & $(0.008)^{* * *}$ & $(0.008)^{* * *}$ \\
\hline \multirow[t]{2}{*}{ FOR } & 0.261 & 0.055 & 0.041 & 0.010 & 0.009 \\
\hline & $(0.016)^{* * *}$ & $(0.020)^{* * *}$ & $(0.006)^{* * *}$ & $(0.008)$ & (0.008) \\
\hline \multirow[t]{2}{*}{$\mathrm{MNE}$} & & 0.261 & & 0.047 & 0.047 \\
\hline & & $(0.015)^{* * *}$ & & $(0.006)^{* * *}$ & $(0.006)^{* * *}$ \\
\hline \multirow[t]{2}{*}{$\ln \frac{K}{L}$} & & & 0.071 & 0.070 & 0.072 \\
\hline & & & $(0.003)^{* * *}$ & $(0.003)^{* * *}$ & $(0.003)^{* * *}$ \\
\hline \multirow[t]{2}{*}{$\ln \frac{M}{L}$} & & & 0.626 & 0.625 & 0.622 \\
\hline & & & $(0.005)^{* * *}$ & $(0.005)^{* * *}$ & $(0.005)^{* * *}$ \\
\hline \multirow[t]{2}{*}{$\ln L$} & & & -0.010 & -0.014 & -0.010 \\
\hline & & & $(0.002)^{* * *}$ & $(0.002)^{* * *}$ & $(0.002)^{* * *}$ \\
\hline \multirow[t]{2}{*}{ age } & & & & & 0.000 \\
\hline & & & & & $(0.001)$ \\
\hline \multirow[t]{2}{*}{$\operatorname{age}^{2} / 10$} & & & & & -0.001 \\
\hline & & & & & $(0.001)$ \\
\hline \multirow{2}{*}{ age $e_{\text {cens }}$} & & & & & -0.003 \\
\hline & & & & & $(0.007)$ \\
\hline obs & 38501 & 38501 & 38501 & 38501 & 38501 \\
\hline
\end{tabular}

Notes: Robust standard errors in parentheses, estimated allowing correlation between unobservables for plants in the same firm. In columns 1-3 the dependent variable is log real value added (at factor cost) per employee. In columns 4-6 dependent variable is plant's real gross output per employee. Both value added and gross output are deflated by 4-digit annual output price deflators. Age cens equals one if the plant exists since 1980. All regressions include region and 4-digit industry time interaction dummies. US equals one if a plant $\mathrm{s}$ owned by a US multinational, $M N E$ is one for all plants part of MNE firms and FOR is one for all plants owned by non US foreign multinationals. ${ }^{*}$ significantly different from zero at the 10 percent level. ${ }^{* *}$ significantly different from zero at the 5 percent level. ${ }^{* * *}$ significantly different from zero at the 1 percent level.

\section{Foreign or Multinational Effect?}

The labour productivity advantage of multinationals, US and non US, reported in row 1 of table 2 might reflect the fact the MNEs tend to operate in highly productive industries and/or tend to cluster in particular regions with special geographical advantages.

Thus, we start our econometric analysis by controlling for interacted 4-digit industry time fixed effects and regional dummies. The results of this exercise are reported in column 1 of table 3 , where we regress labour productivity, measured as real value added per employee on 4-digit industry year dummy interactions, 10 regional dummies and two ownership dummies $U S$, which equals 1 when a plant is a subsidiary of a US multinational, and FOR that takes value 1 when a plant is owned by a foreign, non US, corporation.

We find that US and other foreign owned plants are on average 42 percent and 30 per- 


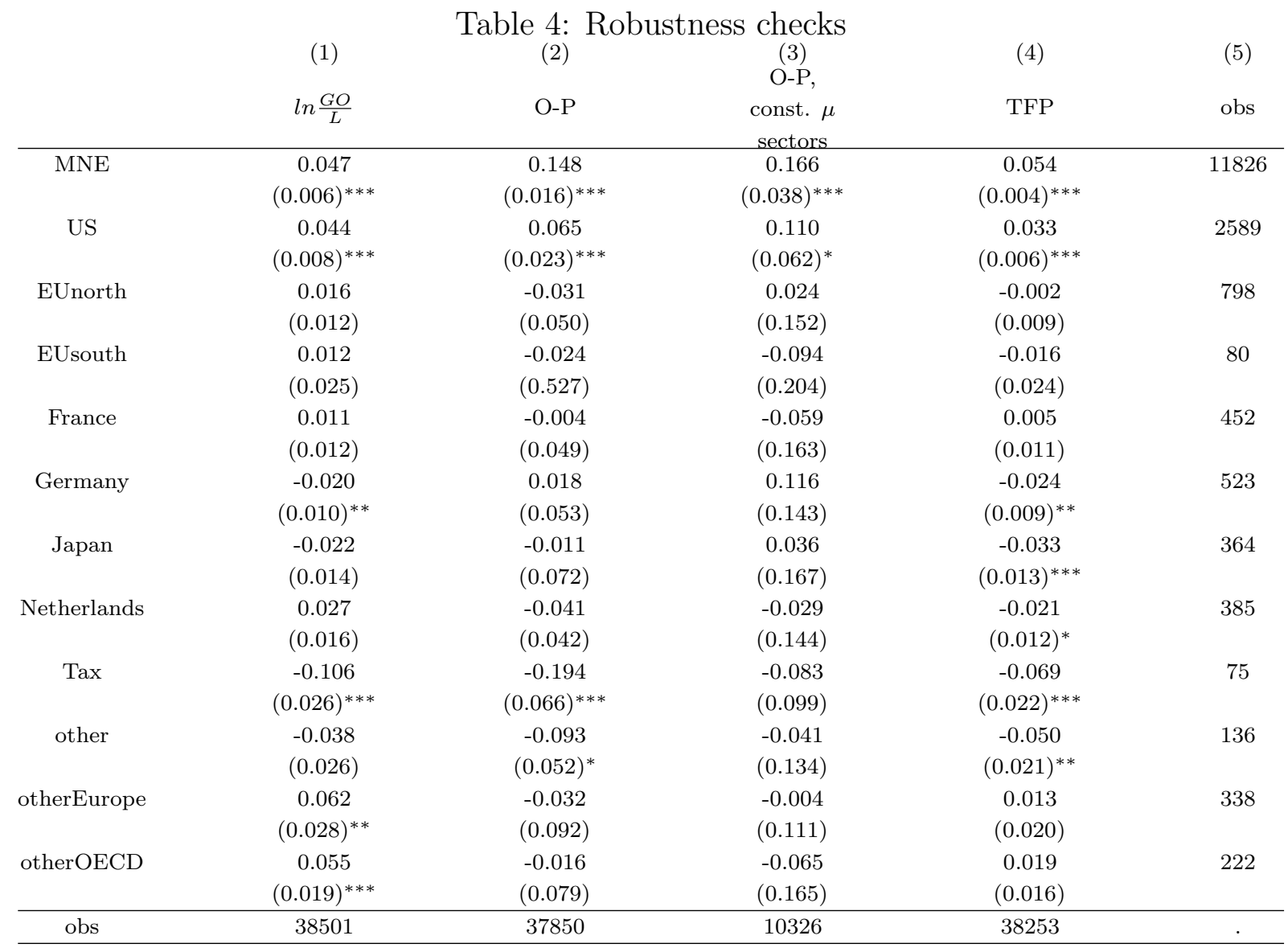

Notes: All regressions include a quadratic polynomial in age, age dummy, time and region dummies not reported in the table for brevity. Columns 1 and 4: robust standard errors in parentheses, estimated allowing correlation between unobservables for plants in the same firm. Columns 2 and 3: bootstrapped standard errors in parentheses. MNEs takes value 1 if plant is part of an MNE group. $U S$ is one if the MNE group is US-owned. Similarly for the other country groups. Details on the country group classifications are in the appendix A. In column 1 the dependent variable is log real gross output per employee. Column 1 estimates a Cobb-Douglas production function. Unreported regressors include log capital per employee, log materials per employee, log employment, and time 4-digit industry interaction dummies.

Columns 2 and 3 report the second stage estimates using a modified version of Olley and Pakes approach described in section 5. Column 3 restricts the sample to plants in sectors where the test of constant markups $\mu$ could not be rejected (see appendix C). In Column 4 the dependent variable is log real TFP calculated using a factor share method as described in section 5.5. ${ }^{*}$ significantly different from zero at the 10 percent level. ${ }^{* *}$ significantly different from zero at the 5 percent level. ${ }^{* *}$ significantly different from zero at the 1 percent level. Column 5 row 1 reports the number of observations for all MNEs in the sample, row 2 reports the number of observations for US MNEs, row 3 to 13 report the number of observations from MNEs in each country group reported in column 1. 
cent respectively more productive than British domestic plants. ${ }^{14}$ This sizeable advantage is in line with previous results for Great Britain (e.g. Oulton (2000). But, how much of this advantage is due to these plants being part of a multinational enterprise? Column 2 answers this question by including a multinational dummy $M N E$ that is one whenever a plant is owned by a multinational firm. If this multinational is US owned the dummy $U S$ will be one as well. Consequently, in column 2 the $U S$ coefficient measures the advantage of US MNEs over British MNEs and the FOR coefficient represents the advantage of non US foreign owned subsidiaries over British MNEs. ${ }^{15}$ The coefficients' estimates reported in column 2 show that MNEs enjoy a productivity advantage of 30 percent, the US have a significant additional advantage of 15 percent, while non US foreign owned plants enjoy a smaller but significant 5 percent advantage relative to their British counterparts.

Table 2 has shown that both US and foreign MNEs have much higher capital intensity than UK firms. This suggests that part of the observed foreign ownership advantage could be driven by this higher capital intensity. To examine this we need to estimate total factor productivity (TFP). The literature has suggested a variety of different approaches to estimating plant level TFP. We start in this section by estimating a Cobb-Douglas production function by OLS. Thus, we assume that output, $Q$, is produced using the technology

$$
q_{i t}=\gamma \sum_{z \in Z} \alpha_{z} x_{z i t}+a_{i t}
$$

where $q_{i t}$ is the logarithm of output produced at plant $i$ in period $t, \gamma$ is the returns to scale coefficient, $Z$ is a set of production factors - labour, physical capital and intermediate inputs $-\alpha_{z}$ are the production function parameters, and $a_{i t}$ is TFP. We examine if TFP systematically varies between various types of MNEs and domestic plants by estimating the following equation

$$
\begin{aligned}
r_{i t}-p_{I t}-x_{L i t}= & \gamma \sum_{z \in Z} \alpha_{z}\left(x_{z i t}-x_{L i t}\right)+\frac{\gamma}{x}{ }_{L i t} \\
& +\beta_{1} U S_{J(i, t)}+\beta_{2} F O R_{J(i, t)}+\beta_{3} M N E_{J(i, t)} \\
& +\theta_{I t}+\psi_{R}+\varepsilon_{i t}
\end{aligned}
$$

\footnotetext{
${ }^{14}$ The percentage differences reported in the text are calculated from the coefficients of the dummy variables in Table 3 according to the formula diff $=\left(e^{\beta^{\text {dummy }}}-1\right)$ e.g. for the US $0.42=\left(e^{0.349}-1\right)$.

${ }^{15}$ The performance of US MNEs relative to domestic plants can, therefore, be calculated as the sum of the coefficients on $M N E$ and $U S$ and the advantage of other foreign-owned plants as the sum of the coefficients on $M N E$ and FOR.
} 
i.e. we regress deflated revenue, $r_{i t}-p_{I t}$, per worker, $x_{L i t}$, on indexes of inputs, dummies referring to ownership ${ }^{16}$ and interacted dummies, $\theta_{I t}$, controlling for 4 digit sectors time effects and 10 regional dummies $\psi_{R}$ to control for location effects within Britain. This approach - although standard practice - raises a number of concerns, such as imperfect competition, endogeneity, the lack of plant specific price indices etc. We discuss these issues and their importance for our results in the following section, and argue that the qualitative results do not change relative to the simple regression described in equation 2. We therefore start by discussing these results, reported in the last three columns of Table 3 .

In column 3 - besides capital and material intensity and regional and industry time fixed effects - we only include US and non US foreign ownership dummies and find that US owned plants are significantly the most productive plants in Britain enjoying a strong and significant TFP advantage of almost 8 percent (with a coefficient of 7.6 as shown by row 1 of column 3) and non US foreign owned plants follow with an advantage of 4 percent relative to the reference group of all British plants. This confirms previous results (e.g. Griffith (1999), Oulton (2000) and Harris (1999)).

Column 4 shows that once we include a separate dummy for being part of an MNE, the advantage of non US foreign MNEs drops to an insignificant 1 percent. US plants maintain a significant advantage of 4.5 percent relative to British MNEs, who, in turn, are 4.8 percent more productive than non MNE plants. This result shows that only part of the US productivity advantage is actually a multinational effect.

Finally, column 5 extends the results of the previous column: it accounts for age effects by including a quadratic polynomial in age, ${ }^{17}$ to account for possible differences due to the plants' life cycle, learning effects and/or the age of physical assets. The coefficient of US MNE remains virtually unchanged, while the foreign non US advantage relative to GB MNEs is a non significant 1 percent. Finally, MNEs are on average 4.6 percent more productive than British non MNEs.

Our results thus suggest the following. Firstly, controlling for capital intensity, material usage, scale and age effects, US MNEs are the productivity leaders, with British and non-US foreign MNEs having a comparable productivity advantage with respect to

\footnotetext{
${ }^{16} U S_{J(i, t)}$, for example, would be equal to 1 if plant $i$ is owned in period t by US firm J.

${ }^{17}$ Since our age variable is left censored in 1980, we include an age censoring dummy. We have tried alternative specifications for the age effect. We also experimented with including age categories and the logarithm of age which leads to the same conclusions as obtained under the current specification.
} 
British plants that are not part of an MNE. Secondly, much of the US and all of the non US foreign productivity advantage found in previous studies ${ }^{18}$ appears to be an MNE effect.

\section{$5 \quad$ Are our results robust?}

Several issues arise when estimating Equation 2. These include our simple grouping of countries into US and all other non UK countries and issues about estimation and interpretation of TFP, such as the perfect competition assumption underlying equation 2 , the inflexibility of our production technology and endogeneity problems. We address these in this section. Our main tool to account for endogeneity is a modified version of the framework suggested by Olley and Pakes (1996), which is new to the literature.

\subsection{Country grouping}

The aggregation of all non-US foreign owned plants in one group might hide considerable heterogeneity. In column 1 of table 4, we differentiate the 'non US Foreign' group further into various country groups. ${ }^{19}$ We see that US MNEs are still the productivity leaders together with Norway, Switzerland and other OECD countries (mainly Canada and Australia), but as a first glance at the following columns shows, only the US leadership is robust to further checks.

\subsection{Imperfect competition}

As pointed out in the previous section, an implicit requirement for the foreign dummies to reflect a purely technological advantage is perfect competition. To examine the implications of removing the perfect competition assumption we find it useful to follow the model originally introduced by Klette and Griliches (1996). Start by simply recalling the definition of deflated revenue, our actual observed dependent variable at the plant level:

$$
r_{i t}-p_{I t}=q_{i t}+p_{i t}-p_{I t}
$$

\footnotetext{
${ }^{18}$ cited in footnote 2.

${ }^{19}$ details of the country groups classification can be found in Appendix A.
} 
i.e. revenue is quantity times prices (all variables in $\operatorname{logs}$ ), $q_{i t}+p_{i t}$, since we do not observe prices at the plant level, we deflate nominal sales using (four-digit) sector level price deflators $p_{I t}$. Given that plant level prices are not observed we need some way of controlling for them with variables we actually observe. This can be done by specifying a demand function which links prices to output. A possible specification of the demand function is (see also Melitz (2000)):

$$
Q_{i t}=\left(\frac{P_{i t}}{P_{I t}}\right)^{-\eta} \Lambda_{i t}^{\eta-1} \Theta_{I t}
$$

where subscripts $i$ denote firm and $I$ industry; $\Lambda_{i t}$ is a firm specific demand shock, $\eta$ is the industry demand elasticity and $\Theta_{I t}$ is a sectoral shock to demand. ${ }^{20}$ Taking logs of Equation 4 and inverting gives:

$$
p_{i t}-p_{I t}=\frac{1}{\mu} \lambda_{i t}-\frac{1}{\eta} q_{i t}+\frac{1}{\eta} \theta_{I t}
$$

where $\mu=\frac{1}{1-\frac{1}{\eta}}$ is the markup of price over marginal cost implied by profit maximizing behaviour and lower case letters denote logarithms.

Combining equations 5 and 1 with 3 gives:

$$
r_{i t}-p_{I t}=\frac{\gamma}{\mu} \sum_{z \in Z} \alpha_{z} x_{z i t}+\omega_{i t}+\frac{1}{\eta} \theta_{I t}
$$

where $\omega_{i t}=\frac{1}{\mu}\left(a_{i t}+\lambda_{i t}\right)$. Equation 6 is the equivalent of Equation 2 under imperfect competition. A number of things are worth pointing out. Firstly, - as stressed by Klette and Griliches (1996) - the interpretation of the estimated coefficients on the various production factors changes: they are now all divided through by the markup coefficient $\mu$. Secondly - and more importantly for our purpose - without plant level price information it is no longer possible to regard TFP, here denoted as $\omega_{i t}$ as a shift parameter relating solely to technical efficiency. ${ }^{21}$ Rather, $\omega_{i t}=\frac{1}{\mu}\left(a_{i t}+\lambda_{i t}\right)$ is a composite of both technology shocks $a_{i t}$, demand shocks $\lambda_{i t}$ and mark-up $\mu$. In the light of equation 6 , how do we interpret the MNE, US and FOR dummies? Let us start by assuming that within 4-digit sectors $\mu$ is constant. In this case a higher $\omega_{i t}$ for US and MNE plants reflects better product quality or consumer valuation, $\lambda_{i t}$, and/or higher technical efficiency, $a_{i t}$.

\footnotetext{
${ }^{20}$ This demand function can be derived by assuming monopolistic competition à la Dixit-Stiglitz (see Dixit and Stiglitz, 1977) in the product market.

${ }^{21}$ Melitz (2000) stresses this point.
} 
However, as some recent papers ${ }^{22}$ have pointed out, revenue based measures of TFP $\left(\omega_{i t}\right)$ might vary between plants for reasons other than product quality or consumer valuation and technical efficiency. In particular, variations in market power - i.e. $\mu$ not being constant across plants in the same industry- might explain some of the variation. Market power might well be positively related to the composite of technical efficiency and product quality. This would introduce a bias to TFP estimates which is negatively correlated with true $\mathrm{TFP}^{23}$ In the worst case - if e.g. market power derives from government regulation and restrictions to entry for example - there might be no systematic relation between market power and biases to TFP estimates.

We have three reasons which suggest that our results are not driven by market power effects. Firstly, while there are surely some sectors of the UK economy in which government regulation rather than competitive pricing determine the market share of different companies $^{24}$ it is hard to believe that this is a general phenomenon in the manufacturing sector as a whole. Consequently we expect, that variations in market power are generally driven by variations in product quality or consumer valuation $\left(\lambda_{i t}\right) .{ }^{25}$ Following the argument in the last paragraph, the biases from variations in market power would then strengthen our main conclusions: if we tend to underestimate TFP of the better plants such as US MNEs but we still find that they are significantly better, then the result would be even more clear-cut if we would correct for these biases. Moreover if regulation favours certain firms then this should in particular lead to advantages for domestic firms rather than MNE firms in general or US firms in particular. Secondly, large variations in market power might be a particular problem when comparing MNEs with non MNEs. However, this should be less of an issue when comparing (British) MNEs, with other (US and other foreign) MNEs. Thirdly, we have devised a simple test based on over identifying restrictions of the assumption that $\mu$ in equation 6 is constant. ${ }^{26}$ The hypothesis that $\mu$

\footnotetext{
${ }^{22}$ see for example Foster, Haltiwanger and Syverson (2003), Syverson (2004) and Katayama, Lu and Tybout (2003).

${ }^{23}$ If in equation 6 the coefficients on factor inputs vary because of variation in market power across plants $\left(\mu_{i t}\right)$ but our estimation model uses fixed coefficients $\overline{\mu_{t}} \in\left[\min \left\{\mu_{i t}\right\} ; \max \left\{\mu_{i t}\right\}\right]$ and $\operatorname{Cov}\left(\mu_{i t}, a_{i t}+\lambda_{i t}\right)>0$, then for plants with high $a_{i t}+\lambda_{i t}$ we attribute too much output variation to production factors. More intuitively, this is the case because our regression model does not control for the fact that for plants with larger $\mu$ an increase in factors would depress prices more.

${ }^{24}$ Sectors where this might be the case include petroleum and nuclear fuel (SIC 23) and Utilities (SIC 40/41) which we exclude from the analysis.

${ }^{25} \mathrm{~A}$ positive relationship between market power and consumer valuation is also the finding of Foster et al. (2003) who investigated the issue on one of the few productivity datasets which includes firm level prices.

${ }^{26}$ The details of this test are reported in Appendix C
} 
is constant is rejected in a large number of sectors. However, if we re-compute our earlier regressions for the sectors in which a constant $\mu$ cannot be rejected, i.e. in those sectors in which market power should not affect the estimated ranking, we come to the same qualitative conclusions on the relative position of various groups of MNEs.

\subsection{A more flexible production function allowing for imperfect competition}

An additional worry might be that a log linear production function is inappropriate. Klette (1999) has proposed a methodology that integrates a flexible production function into an imperfectly competitive setting. The starting point is a homogenous differential production function:

$$
Q_{i t}=A_{i t}\left[f\left(\mathbf{X}_{i t}\right)\right]^{\gamma}
$$

where $\mathbf{X}_{i t}$ is a vector of factor inputs and $f(\cdot)$ is a linear homogenous general differentiable function. Using the mean value theorem we can write output relative to the median firm as:

$$
\tilde{q}_{i t}=\tilde{a}_{i t}+\sum_{z=1}^{Z} \alpha_{z} \tilde{x}_{z i t}
$$

where small letters with a tilde denote log deviations from the median plant $(\mathcal{M})$ in a given year, ${ }^{27}$ and the $\alpha_{z}$ represent the partial derivatives of the log production function evaluated at some point $\overline{\mathbf{X}}_{i t}$ in the convex hull spanned by $\mathbf{X}_{i t}$ and $\mathbf{X}_{\mathcal{M} t}$, so that

$$
\alpha_{z}=\gamma f_{z}\left(\overline{\mathbf{X}}_{i t}\right) \frac{\bar{X}_{z i t}}{f\left(\overline{\mathbf{X}}_{i t}\right)}
$$

where $f_{z}(\cdot)$ represents the partial derivative of $f(\cdot)$ with respect to production factor $z$. The first order condition of profit maximization implies that

$$
P_{i t} \gamma \frac{Q_{i t}}{f\left(\mathbf{X}_{i t}\right)} f_{z}\left(\mathbf{X}_{i t}\right)=\mu W_{z i t}
$$

\footnotetext{
${ }^{27}$ e.g. $\tilde{q}_{i t}=\ln Q_{i t}-\ln Q_{\mathcal{M} t}$
} 
i.e. prices are such that the marginal value product is $\mu$ times the marginal cost $W$ of each factor. Our demand function implies that

$$
\mu=\frac{1}{1-\frac{1}{\eta}}
$$

As pointed out by Klette (1999), equation 10 can only be expected to hold for production factors which are easily adjustable. We assume that this is the case for intermediates and labour, but not for capital so that we get:

$$
\alpha_{z}=\mu \frac{W_{z} X_{z i t}}{P_{i t} Q_{i t}}=\mu s_{z i t}
$$

where $s_{z i t}$ is the revenue share of factor $\mathrm{z}$ and $z \in\{L, M\}$. Further, because of homogeneity of degree $\gamma$ of the production function we get

$$
\alpha_{K}=\gamma-\alpha_{L}-\alpha_{M}
$$

and therefore in equation 8:

$$
\tilde{q}_{i t}=\tilde{a}_{i t}+\mu \tilde{v} i_{i t}+\gamma \tilde{k}_{i t}+\tilde{a}_{i t}
$$

where

$$
\tilde{v i}_{i t}=\sum_{z \neq K} \bar{s}_{j t}\left(\tilde{x}_{z i t}-\tilde{k}_{i t}\right)
$$

is an index of all variable factors. These results allow us to rewrite 6 as $^{28}$

$$
\tilde{r}_{i t}-\tilde{v} i_{i t}=\frac{\gamma}{\mu} \tilde{k}_{i t}+\tilde{\omega}_{i t}
$$

The variable factor index $\tilde{v} i_{i t}$ can be directly observed from the data, since all that is required are variables for factor inputs and revenue shares of the factors. ${ }^{29}$

\footnotetext{
${ }^{28} \mathrm{All}$ aggregate expressions such as $p_{I t}$ and $\theta_{I t}$ in 6 disappear because the equation is now written in terms of deviations from the median plant in the sector.

${ }^{29}$ Equation 9 suggests that we should evaluate the derivatives - and thus the factor shares - at 'some point in the convex hull'. Since we do not know the exact location of this point and of course we do not know the functional form of the derivative, we follow common practice and approximate by averaging over the factor share at plant $i$ and the factor share at the median plant $\mathcal{M}$ to calculate the shares in $v i_{i t}$; i.e. $\bar{s}_{i t}=\frac{s_{M t}+s_{i t}}{2}$. See also Baily et al. (1992) on this.
} 


\subsection{Accounting for endogeneity}

Equation 15 suggests that the final element required to derive an estimate for $\tilde{\omega}_{i t}$ is to find an estimate of $\beta_{K}=\frac{\gamma}{\mu}$, the ratio between the scale and the markup coefficient. Since plant level capital stocks - like all other inputs - are presumably highly correlated with $\tilde{\omega}_{i t}$ this is not a trivial undertaking. ${ }^{30}$ We address this problem using a modified version of the approach of Olley and Pakes (1996). Following them we assume that $\tilde{\omega}_{i t}$ evolves as a first order Markov Process:

$$
\tilde{\omega}_{i t}=E\left\{\tilde{\omega}_{i t} \mid \tilde{\omega}_{i t-1}\right\}+\tilde{\nu}_{i t}
$$

We also assume that capital is only correlated with the expected component of $\tilde{\omega}_{i t}$ but not with $\tilde{\nu}_{i t}{ }^{31}$ Then we can estimate equation 15 if we find a control for $E\left\{\tilde{\omega}_{i t} \mid \tilde{\omega}_{i t-1}\right\}$. In Appendix B we show that conditional on capital and assuming that markups $\mu$ are constant across firms in a narrowly defined sector (four digit) there is a monotone relationship between profits - defined as revenue minus variable costs - and $\tilde{\omega}$. Consequently we can invert the profit function and write

$$
\tilde{\omega}_{i t}=\phi_{\omega}\left(\tilde{k}_{i t}, \tilde{\Pi}_{i t}\right)
$$

We do not know what functional form $E\left\{\tilde{\omega}_{i t} \mid \cdot\right\}$ takes, but in equation 17 we have found a way to express it in terms of observables so that we can rewrite 15 as

$$
\tilde{r}_{i t}-\tilde{v} i_{i t}=\frac{\gamma}{\mu} \tilde{k}_{i t}+g\left(\tilde{k}_{i t-1}, \tilde{\Pi}_{i t-1}\right)+\tilde{\nu}_{i t}
$$

where $g(\cdot)=E\left\{\tilde{\omega}_{i t} \mid \phi(\cdot)\right\}$ is a function of unknown form. To estimate 18 we can either employ a semi-parametric procedure or approximate $g(\cdot)$ by a third order polynomial which, for simplicity, is our strategy. An estimator for $\tilde{\omega}_{i t}$ can then be obtained as

$$
\hat{\tilde{\omega}}_{i t}=\tilde{r}_{i t}-\tilde{v i}_{i t}-\widehat{\left(\frac{\gamma}{\mu}\right)} \tilde{k}_{i t}
$$

Compared to Olley and Pakes (1996) the main innovation of our approach is to use

\footnotetext{
${ }^{30}$ see Griliches and Mairesse (1995) for a summary on the endogeneity problem and potential solutions.

${ }^{31}$ Olley and Pakes assume that investment in $t$ can only be used for production in $t+1$. We follow a different strategy. We assume that investment is predetermined. Although this would be problematic in the Olley and Pakes methodology, it does not affect our estimation procedure.
} 
profits and not investment as predictor for $\tilde{\omega}_{i t}$. This has a number of advantages. Firstly, a major criticism of the Olley and Pakes framework is that investment might be a very poor predictor of the fixed component of $\tilde{\omega}_{i t}{ }^{32}$ If firms are essentially in the steady state - and the capital stock in period $t$ reflects the firm's knowledge about $\tilde{\omega}_{i t}$ at $t-1$ - then the variation in investment reflects primarily adjustments to news about $\tilde{\omega}$ from period $t$. Our approach - similarly to Levinsohn and Petrin ( 2000) who use material inputs instead of investment - does not suffer from this problem. Plants with high $\tilde{\omega}$ will have higher profits whether or not they are in the steady state. Secondly, differently from Levinsohn and Petrin, we can identify all relevant parameters from a moment condition on capital without having to assume separability in intermediate inputs or relying on instrumental variable techniques. Also, we do not require any assumptions on the substitutability between variable production factors. ${ }^{33}$

Finally, to examine if measured TFP $\left(\tilde{\omega}_{i t}\right)$ is systematically different between various types of MNEs we run a regression of estimated $\tilde{\omega}_{i t}$ on our ownership dummies.

$$
\hat{\tilde{\omega}}_{i t}=\beta_{1} U S_{J(i, t)}+\beta_{2} F O R_{J(i, t)}+\beta_{3} M N E_{J(i, t)}+\tilde{\varepsilon}_{i t}
$$

Column 2 of table 4 reports the results of this exercise. We see that controlling for endogeneity and allowing for imperfect competition, non constant returns to scale as well as for a very flexible production technology has no qualitative and only small quantitative implications for our results. Column 3 shows estimates computed with the same method, but including in the second stage regression - equation 20 - only those sectors for which our test ${ }^{34}$ of constant markups $\mu$ could not be rejected. This suggests the same qualitative conclusions as before.

\subsection{Other approaches to TFP estimation}

The simplest way to handle the endogeneity problem in production function estimation is to follow a factor share approach which involves no regression analysis at all. In table 4 - for completeness - we also report our results from using such an approach. Following Baily et al. (1992) and adopting a strategy similar to the one used to calculate the variable

\footnotetext{
${ }^{32}$ see Griliches and Mairesse (1995).

${ }^{33}$ For a more detailed discussion of our approach see Martin (2003).

34 as described in Appendix C
} 
factor index $v i_{i t}$ in the previous subsection ${ }^{35}$ we calculate TFP as

$$
\tilde{\omega}_{i t}^{B H C}=\tilde{r}_{i t}-\bar{s}_{M i t} \tilde{m}_{i t}-\bar{s}_{L i t} \tilde{l}_{i t}+\left(1-\bar{s}_{M i t}-\bar{s}_{L i t}\right) \tilde{k}_{i t}
$$

Column 4 shows that even under this specification our main results of a general MNE advantage and a further US advantage prevail. Note, however, that the point estimates found for the MNE and US effects are considerably smaller compared to results in columns 1 and 2. This is a consequence of imposing $\frac{\gamma}{\mu}=1$ which we implicity do in equation 21 . If we use the TFP estimation strategy described in the previous sections we typically find $\frac{\gamma}{\mu}<1$ suggesting the prevalence of imperfect competition. Now if there is a positive correlation between performance and capital input $\left(\operatorname{Cov}\left(\omega_{i t}, k_{i t}\right)>0\right)$ then standard TFP assigns too much of the variation in $r_{i t}-v i_{i t}$ (see equation 15) to capital so that better performing plants look worse than they are. ${ }^{36}$

To summarize, the results shown in table 3 seem to be robust: US MNEs are the most productive with British MNEs and foreign non US MNEs alternating each other in the second position. British plants that are not part of an MNE are the least productive. In the next section we shed more light on the factors, which drive these differences. ${ }^{37}$

\section{Explaining the US productivity leadership}

In the previous sections we have been able to establish two main results. Firstly, plants owned by MNEs are on average more productive than non MNE plants and secondly, plants owned by US MNEs are more productive than all other MNEs. Using the longitudinal dimension of the current data we try to distinguish between three hypotheses on the sources of the MNE and US advantages.

\footnotetext{
${ }^{35}$ This approach is equivalent to imposing $\frac{\gamma}{\mu}=1$ which rules out imperfect competition and nonconstant returns to scale.

${ }^{36}$ An alternative method to estimate TFP controlling for the endogeneity of inputs would be Difference GMM (Arellano and Bond (1991)) and System GMM (Blundell and Bond (1998)). We attempted to use these estimation methods on our sample, but we encountered two problems: firstly the time period of our sample is too short, 5 years, with less than 7 percent of the plants observed over the whole time period; secondly, due to the fact that the ARD surveys small plants randomly, only 12 percent of the plants have continuous time series information.

${ }^{37}$ Other unreported robustness checks include weighted regressions and regressions that control for unobserved skill level in the firm. In the latter we include in equation 2 plant average wage as a proxy for the average skill level of workers; we cannot further distinguish between average wage for operatives and average wage for administrative employees unlike previous studies (e.g. Griffith and Simpson (2001)) because since 1996 this information has not been reported in the ARD.
} 
Table 5: Sources of MNE and US advantage (Productivity is residual of gross output regression)

\begin{tabular}{cccc} 
& $(1)$ & $(2)$ & $(3)$ \\
& all & change to MNE & currently domestic \\
\hline MNE & 0.007 & 0.007 & 0.007 \\
& $(0.007)$ & $(0.008)$ & $(0.007)$ \\
ever MNE firm & 0.066 & 0.018 & 0.160 \\
ever MNE plant & $(0.013)^{* * *}$ & & $(0.025)^{* * *}$ \\
& 0.155 & & -0.023 \\
ever US firm & $(0.025)^{* * *}$ & $(0.020)$ & 0.121 \\
& -0.002 & 0.120 & $(0.024)^{* * *}$ \\
ever US plant & $(0.017)$ & $(0.032)^{* * *}$ & 0.009 \\
ever other for firm & 0.098 & $(0.019)$ & $(0.020)^{*}$ \\
& $(0.016)^{* * *}$ & 0.017 & 0.001 \\
ever other for plant & 0.017 & $(0.026)$ & $(0.012)$ \\
green dom & $(0.014)$ & 0.022 & 0.081 \\
& 0.048 & $(0.033)$ & $(0.057)$ \\
green mult & $(0.015)^{* * *}$ & & -0.087 \\
green US & -0.007 & & $(0.072)$ \\
green other & $(0.010)$ & & -0.010 \\
& 0.037 & & $(0.072)$ \\
\hline obs & $(0.016)^{* *}$ & & 25558 \\
\hline
\end{tabular}

Notes: Bootstrapped standard errors in parentheses. Row 1 (MNE) reports first-stage estimates of the going global effect. Row 2 and below: coefficients and standard errors are from the second-stage of our estimation procedure. Dependent variable is fixed effects estimated in the first step. ever MNE firm equals 1 if the plant belongs at time $t$ to a firm which is MNE. ever MNE plant is 1 if the plant has ever been owned by a MNE over the course of the sample period. Similarly for the ever US and ever FOR dummies. green dummies take value one for all plants that are established during the course of the sample period (1996-2000), green GB non MNE is one for plants owned by domestic firms when established. green MNE is one for plants owned by MNE firms when established. green US (green FOR) is one for plants owned by US (other foreign) firms when established. Column 1 use the whole sample of 38,501 observations. Column 2 only includes plants that incur a change in status over the period they are present in the sample. Column 3 only keeps observations of non MNE plants and of MNE plants when owned by non MNE firms. * significantly different from zero at the 10 percent level. ${ }^{* *}$ significantly different from zero at the 5 percent level. ${ }^{* * *}$ significantly different from zero at the 1 percent level.

A first hypothesis is that plants owned by MNEs might be more productive because multinational firms takeover the best plants in any country. We call this the plant picking effect. This might be because multinational corporations have more resources to finance takeover activity or because they are simply better at spotting top performing plants.

A second hypothesis is that multinational firms are characterised by superior shared assets that improve the performance of any plant they takeover. ${ }^{38}$ Examples include international distribution networks, special management techniques, patents, blueprints, trade secrets, and reputation effects. We refer to this as the best firm effect.

Finally, plants owned by firms that start investing abroad might experience productivity improvements as a direct consequence of FDI, because of, for example, firm-level scale economies, cheaper options to hedge against exchange rate risk, technology sourcing

\footnotetext{
${ }^{38}$ we can think of this effect as the 'ownership specific' factors in Dunning's explanation of FDI or the 'knowledge capital' of the firm in Markusen.
} 
Table 6: Status changes in the data

(Transitions in ownership and MNE status in sample 1996-2000)

(1)

GB non MNE
(2) GB MNE
(3)

US
(4) FOR

\begin{tabular}{|c|c|c|c|c|}
\hline \multicolumn{5}{|c|}{ Status changes } \\
\hline GB Non MNE & 11164 & 589 & 225 & 304 \\
\hline GB MNE & 251 & 3170 & 101 & 46 \\
\hline US & 155 & 62 & 1290 & 48 \\
\hline FOR & 138 & 42 & 26 & 1857 \\
\hline \multicolumn{5}{|c|}{ Status changes with ownership change } \\
\hline GB Non MNE & 1511 & 255 & 225 & 304 \\
\hline GB MNE & 164 & 51 & 101 & 46 \\
\hline US & 155 & 62 & 131 & 48 \\
\hline FOR & 138 & 42 & 26 & 246 \\
\hline
\end{tabular}

Notes: GBnon $M N E$ denotes domestic plants with no FDI; GBMNE is one for all domestic multinationals; $U S$ is one for all plants owned by a US multinational and FOR is one for all plants owned by non US foreign multinationals. The table reports in panel one the number of plants that change their MNE status; in panel two the subset of these that also experienced an ownership change. For example Row 1 Column 2 reports that there are 589 transitions from GB non MNE to GB MNE. Row 5 Column 2 reports that in 255 cases these transitions also involved a takeover. Number of observations in the sample is 38,501. The period considered is 1996-2000. Source: Authours' calculation using the ARD AFDI matched data.

from abroad or other learning effects. We call this the going global effect.

We represent these hypotheses formally as follows. ${ }^{39}$ Productivity, Prod $_{i t}$, of plant $i$ at time $t$ can be written as ${ }^{40}$ :

$$
\operatorname{Prod}_{i t}=\alpha_{i}+\zeta_{t, J(i, t)}+\varepsilon_{i t}
$$

where $\zeta_{t, J(i, t)}=\zeta_{J(i, t)}+\beta_{M N E} M N E_{J(i, t)}$; i.e. productivity can be decomposed in an effect $\zeta_{t, J(i, t)}$ due to the parent firm of plant $i$ at time $t$ and a plant specific effect $\alpha_{i}{ }^{41}$ $\zeta_{t, J(i, t)}$ is then decomposed further in a time invariant firm specific effect $\zeta_{J(i, t)}$ and an effect which allows a causation from becoming multinational to productivity, $\beta_{M N E}$. In this setting the best firm effect can be represented as

$$
E\left\{\zeta_{J(i, t)} \mid M N E_{J}^{e v e r}=1\right\}>E\left\{\zeta_{J(i, t)} \mid M N E_{J}^{e v e r}=0\right\}
$$

where $M N E_{J}^{e v e r}$ is a time invariant dummy variable that is equal to one if firm $\mathrm{J}$ is a multinational, British ${ }^{42}$ or foreign, i.e. for MNEs we expect a higher firm fixed effects

\footnotetext{
${ }^{39}$ For simplicity at this stage we do not separate the MNE group further into separate US and foreign other (FOR). We reintroduce those in the empirical analysis below.

${ }^{40}$ In principle we can decompose any productivity measure in this way. In our actual estimations below we use TFP calculated as the residual from equation 2 as reported in column 5 of table 3 .

${ }^{41}$ For simplicity we abstract from differences between various types of MNEs.

${ }^{42}$ Note that, for a given firm, $M N E_{J}^{e v e r}$ is time invariant characteristic. So for a UK MNE it would be
} 
than for other firms. The plant picking effect, on the other hand, can be represented as

$$
E\left\{\alpha_{i} \mid M N E_{i}^{e v e r}=1\right\}>E\left\{\alpha_{i} \mid M N E_{i}^{e v e r}=0\right\}
$$

where $M N E_{i}^{e v e r}$ is a dummy that is equal to one if plant $i$ is being owned at some point in the sample by a multinational firm in the periods when this firm is actually investing abroad. ${ }^{43}$ Finally, the going global effect, is represented as $\beta_{M N E}>0$. To explain how we identify these various effects from our data we introduce an example in figure 1.

Figure 1: An example

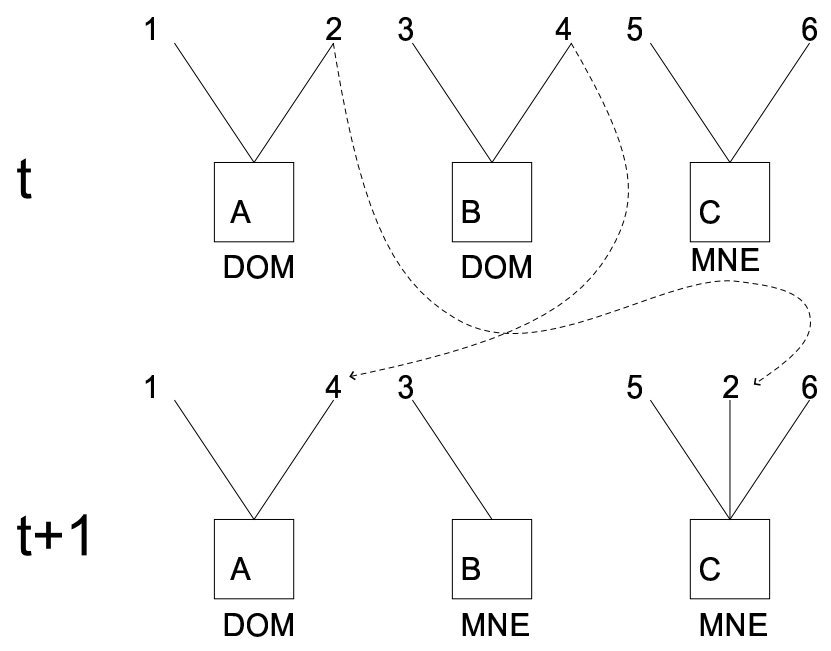

Suppose our sample consists of 6 plants $^{44}$ which are owned by 3 different firms (A, B and $\mathrm{C}$ ). We observe them for two periods, $t$ and $t+1$. In period $\mathrm{t}$ firms $\mathrm{A}$ and $\mathrm{B}$ are domestic, whereas firm $\mathrm{C}$ is an MNE. In period 2 firm B starts investing abroad and thus becomes an MNE whereas A stays domestic. ${ }^{45}$ Moreover, we have the following takeover events: plant 2 is acquired by $\mathrm{C}$ and plant 4 is sold off to firm A by firm B before it starts investing abroad. ${ }^{46}$ How can we differentiate between the various MNE effects discussed earlier with the variation in this example? Consider first the plant picking effect. The one plant in the example that was taken over by an MNE is plant 2. If we found that in year

equal to one even in the years where it has not yet started investing abroad.

${ }^{43}$ This latter qualification is of relevance for British MNEs in periods where they have not yet started investing abroad. Plants which they sell or close down before investing abroad would be classified as non MNE plants owned by an MNE.

${ }^{44}$ numbered 1 to 6 in figure 1

${ }^{45}$ In terms of our earlier dummies we would thus have $M N E_{A}^{e v e r}=0, M N E_{B}^{e v e r}=1$ (both, in year t and $\mathrm{t}+1)$ and $M N E_{C}^{e v e r}=1$

${ }^{46}$ Consequently $M N E_{1}^{\text {ever }}=0$ and $M N E_{4}^{\text {ever }}=0$ whereas for all other plants $M N E_{i}^{\text {ever }}=1 \forall i=$ $2,3,5,6$. 
t plant 2 had a higher productivity than plant 1 this would be evidence of a plant picking effect. To examine the existence of best firm effects we can compare the productivity of plant 2 in year $t+1$ relative to year $t$. If its productivity increases after it is taken over by firm $\mathrm{C}$ this would be evidence of best firm effect. ${ }^{47}$ Finally, for the going global effect we have to look at firm $\mathrm{B}$ and examine if the productivity of its plant 3 increases from $t$ to $t+1$.

How do we implement this econometrically? Our estimation strategy proceeds in two steps. In the first step our objective is to obtain a consistent estimate of $\beta_{M N E}$. Given the assumptions of our model, the source of endogeneity is the potential correlation between the unobserved effects $\alpha_{i}$ and $\zeta_{J}$ and the variable of interest $M N E_{J(i, t)} \cdot{ }^{48}$ Note that if we take deviations of the dependent and explanatory variables from the mean across all observations of a specific firm plant combination, the two fixed effects vanish:

$$
\widetilde{x_{i t}}=x_{i t}-\frac{1}{\#_{i t}[J(i, t)]} \sum_{\tau \text { s.t. } J(i, \tau)=J(i, t)} x_{i \tau}
$$

where $\#_{i t}[\cdot]$ is a function that returns the number of periods plant $i$ is owned by the firm $J(i, t)$. This corresponds to the fixed effects transformation where the cross sectional units are not the plants nor the firms but each firm-plant combination in the dataset. Consequently, running a least squares regression on

$$
\widetilde{\operatorname{Prod}_{i t}}=\widetilde{M E_{J(i, t)}} \beta+\widetilde{\varepsilon}_{i t}
$$

will give us a consistent estimate of $\beta_{M N E} .{ }^{49}$ This, in turn, can be used to obtain an

\footnotetext{
${ }^{47}$ Equally, we could look if the productivity of plant 4 decreases once it is taken over by $\mathrm{A}$ in period $t+1$.

${ }^{48}$ Note that we are assuming $E\left(\varepsilon_{i t} \mid M N E_{J(i, t)}, \zeta_{J(i, t)}, \alpha_{i}\right)=0$, i.e., conditional on the fixed effects, changes in MNE status are not correlated with the time varying shocks. We discuss this assumption in more detail later in this section.

${ }^{49}$ One crucial assumption required is that the change in MNE status is not correlated with the time varying part of the error term. Thus, we are implicitly assuming that the timing of the MNE status change is exogenous. A scenario where this might be violated is the following: plants could have a higher probability of being taken over in years where they suffer from idiosyncratic large negative shocks. To examine the relevance of this scenario we run probit regressions of the probability of changing status to MNE on time dummies and TFP growth in the previous year. The results show that productivity growth is not significantly correlated with the probability of being taken over by an MNE. Also, since we do not have good instruments for changes in MNE status we thought of controlling for the endogeneity of MNE status changes using GMM methods. However, we cannot use these estimation methods as explained in footnote 36 .
} 
estimate of the fixed effects for all firm-plant combinations

$$
\widehat{\zeta_{J(i, t)}+} \alpha_{i}=\operatorname{Prod}_{i t}-\hat{\beta}_{M N E} M N E_{J(i, t)}
$$

Our second stage proceeds by running a regression of the predicted fixed effects on the $M N E_{J}^{e v e r}$ and $M N E_{i}^{e v e r}$ dummies:

$$
\widehat{\zeta_{J(i, t)}+} \alpha_{i}=\beta_{J}^{e v e r} M N E_{J(i, t)}^{e v e r}+\beta_{i}^{e v e r} M N E_{i}^{e v e r}+v_{i t}
$$

The plant picking effect is in this setting represented as $\beta_{i}^{\text {ever }}>0$ and the best firm effect as $\beta_{J}^{\text {ever }}>0$.

Table 5 shows results from this regression exercise. Start by considering column 1 where we regress both stages on the complete sample. Note first that, as in section 4, we control separately for US MNEs and other foreign effects with dummies that are constructed according to the example of $M N E_{J}^{e v e r}$ and $M N E_{i}^{e v e r}$. Moreover, we include a set of dummies that are equal to one if a plant is setup as a greenfield investment during our sample period by either a domestic or an MNE firm. ${ }^{50}$ This is to control for a potentially important source of heterogeneity in the data that could bias our estimate of the best firm effect: if any MNE's shared assets' effects could only be fully realised in plants which are setup as greenfields by multinationals then ignoring these greenfield dummies would bias our firm effects downwards. Consider now the results in column 1. Firstly, row 1 reports the coefficient $\beta_{M N E}$ estimated in the first step. The positive but insignificant coefficient's estimate of 0.007 suggests that there is no strong going global effect. $^{51}$ Row 2 and 3 show that the MNE advantage seems to be due to both a plant picking effect and a best firm effect. We find significant coefficients' estimates of 0.066 and 0.155 , respectively. Looking at row 4 and 5 we also have evidence that the additional US advantage is a consequence of plant picking rather than a best firm effect: plants that are at some point US owned have an average advantage of about 10 percent over all other MNE plants. Row 7 shows a significantly positive foreign non-US plant effect of 4.8 percent, which is lower than the US plant effect.

Finally, rows 8 to 11 report the 'greenfield' effects. Row 9 shows that plants that are

\footnotetext{
${ }^{50}$ The reference category for this set of dummy variables are the plants which were set up before our sample started so that we do not know who set them up.

${ }^{51}$ This first row result is the same in all columns, because the various columns only differ with respect to the second stage regression
} 
setup by MNEs enjoy a 3.7 percent advantage relative to non greenfield domestic plants, significant at the 5 percent level; row 10 and 11 show that there is no additional advantage from being setup by a US or a foreign MNE.

What could be a potential concern with our estimates in column 1? Note that in terms of the example in figure 1 the MNE firm coefficient, $\beta_{J}^{\text {ever }}{ }^{52}$ is calculated as a weighted average of all observations of plants currently owned by an MNE firm minus a weighted average of observations of all plants that are not owned by an MNE. ${ }^{53}$

Thus, $\beta_{J}^{\text {ever }}$ could be high for two reasons. Firstly, if plants such as 3,5 and 6 which throughout the sample period are owned by multinationals are very productive or secondly, if plants such as 2 which change their ownership over the course of our sample had a strong increase in productivity after being taken over by an MNE. ${ }^{54}$ To examine which of the two is more relevant is interesting because it gives us an idea of the time span which might be necessary for MNEs to increase the productivity of the acquired plants. Note, that a particular characteristic of plants such as 5 and 6 is that they have been owned by an MNE for longer than plants such as $2 .{ }^{55}$ Consequently, in column 2 we restrict our sample for the second stage regression to MNE plants which had a transition from domestic to MNE over the course of our sample. ${ }^{56}$ If we still find significant MNE firm effects this is an indication that MNE firms are very quick in improving the productivity of acquired plants. However, in column 2 the MNE firm dummy reduces to less than a third relative to column 1 - from 0.066 to 0.018 - and is only borderline significant. ${ }^{57}$

Equally, there might be an issue with our estimates of the plant picking effects in column 1. The MNE plant picking effect - and by analogy the US and other foreign plant picking effects - are computed as the weighted average of all observations from $M N E^{\text {ever }}$ plants minus a weighted average of all observations from non $M N E^{\text {ever }}$ plants. ${ }^{58}$

Therefore, our calculations also include observations from periods in which some of

\footnotetext{
${ }^{52}$ And by analogy all other firm coefficients in column 1.

53i.e. in terms of the example in figure 1, the best firm effect is calculated as Weighted Average $\left\{2_{t+1}, 3_{t}, 3_{t+1}, 4_{t}, 5_{t}, 5_{t+1}, 6_{t}, 6_{t+1}\right\}$ - Weighted Average $\left\{1_{t}, 1_{t+1}, 2_{t}, 4_{t+1}\right\}$ where $(i, t)$ denotes a plantyear tuple.

${ }^{54}$ or if plants such as 4 had a dramatic drop in productivity after being sold off.

${ }^{55}$ Since we have a sample period of 5 years and for plants such as 2 we must observe at least one takeover, the longest time such a plant could be owned by an MNE is 4 years.

${ }^{56}$ Like example plant 2.

${ }^{57}$ In unreported results, we explore this issue in more detail. We find that if we restrict this analysis to plants that we observe for at least two years after takeover, i.e. to 692 observations, the MNE firm dummy coefficient is estimated to be 0.035 with a bootstrapped standard error of 0.022 .

${ }^{58}$ Thus, in terms of our example, the plant picking effect is calculated as WeightedAverage $\left\{2_{t}, 2_{t+1}, 3_{t}, 3_{t+1}, 5_{t}, 5_{t+1}, 6_{t}, 6_{t+1}\right\}-$ WeightedAverage $\left\{1_{t}, 1_{t+1}, 4_{t}, 4_{t+1}\right\}$
} 
the plants are owned by an $M N E^{e v e r}$ firm. ${ }^{59}$ Thus, the robustness of our plant effects estimator depends on our ability to correctly control for any firm effect that the plants are subject to in those periods. An easy way to check our results is to restrict the second stage regression to the sample of observations in which plants are owned by non MNE firms. ${ }^{60}$ This is done in column 3. As in column 1 we find strong MNE and US plant picking effects suggesting that MNEs and especially US MNEs pick the better plants. In contrast to column 1, we cannot find an additional plant picking effect for plants which are taken over by non US foreign firms.

What other potential concerns arise concerning this analysis? A strong assumption in our identification strategy is that all unobserved heterogeneity can be captured by our two fixed effects. There might be important deviations from this model. For example plants might be acquired by MNEs not according to their productivity level but according to their future growth potential. To investigate this in more detail we would require a dataset covering a longer time period than we have at present. Also note that if this issue is important it would lead in our framework to an overestimation of the firm effects, especially in column 2 where we focus on plants that were taken over by MNEs during the sample period.

Another possible source of endogeneity is related to the possibility that the takeover by an MNE is correlated with time varying shocks as well as the plant fixed effects. For example, the transition to foreign ownership might not only depend on fixed characteristics of plants but also on temporary negative shocks which make the plant temporarily weak and thus a target of e.g. a hostile foreign takeover. Alternatively, one might think of a case in which the MNE gains interest in a particular plant because of a positive productivity shock. It is therefore not clear in which direction the bias will go.

Apart from our estimation strategy, a general concern might be that our dataset does not have sufficient movement of firms between multinational states and of plants between different types of firms. This is the topic of table 6 which reports the occurrence of all these changes in our dataset. The upper panel reports the number of status changes for each possible transition between GB non MNE, GB MNEs, US MNEs and Non US Foreign MNEs (FOR). For example the cell in row 1, column 2 reports that in our sample there

\footnotetext{
${ }^{59}$ in terms of the example these are $(2, t+1)$ and $(4, t)$

${ }^{60}$ i.e. identify the plant effect from WeightedAverage $\{(2, t)\}-$ WeightedAverage $\{(1, t),(1, t+1),(4, t+$ $1)\}$.
} 
are 589 transitions from GB non MNEs to GB MNEs. The lower panel reports only the number of status changes that also involved an ownership change. Therefore, the cell in row 5 column 2 reports that 255 of the 589 British plants that became multinational did so by means of an ownership change, i.e. a takeover. This implies that the remaining 334 plants became part of a British MNE because the firm they belonged to started investing abroad. This is the variation we use to identify $\beta_{M N E}$. In total, the upper panel shows that we have 1,118 changes between non MNE and MNE status. ${ }^{61}$ The lower panel shows that 784 of these changes involved a change in ownership, i.e. a takeover. Overall panel 1 of table 6 shows that about 10 percent of all the transition events we can observe in the data involve a change in multinational status. ${ }^{62}$ From panel 2 we can derive that about 40 percent of all ownership changes in our sample involve changes between multinational status. ${ }^{63}$ Thus, while the majority of plants do not switch status, in the data there is still some non negligible amount of status changes.

To summarize, our results suggest the following. First, in line with the predictions of Dunning, we find evidence for an MNE firm effect. This evidence is stronger when we consider plants which have been part of an MNE for a longer time period. This suggests that MNE firm specific advantages require some time to materialise at the plant level. Second, we find strong and robust evidence of plant picking by MNEs. Third, the US seems to be the best at cherry picking the most productive plants in Great Britain, and indeed this seems to be the source of the additional US advantage found in the OLS regressions. Fourth, there seems to be a small advantage of foreign non US MNE firms in acquiring better plants, although this is significantly smaller than for their US counterparts and not robust across different specifications. Fifth, we do not find any evidence that FDI of British firms has a direct short run beneficial effect on the productivity of plants they own in Britain, but again this result might be driven by the rather small length of our sample period.

\footnotetext{
${ }^{61}$ we obtain this figure by summing the off diagonal elements of row 1 and column 1 in the upper panel. ${ }^{62}$ That's computed as the share of all off diagonal elements to the sum of all cells of table 6 .

${ }^{63}$ Again computed as the share of all off diagonal elements this time of panel 2
} 


\section{Conclusion}

This is the first study which identifies domestic multinationals in the Annual Respondent Database (ARD), the most comprehensive plant level dataset for Great Britain. We find that plants owned by British multinationals in Britain are more productive than plants with no international involvement. While British MNE plants have on average the same productivity as foreign owned plants, we find a significant productivity advantage of US owned plants. This evidence makes several contributions to the literature. Firstly it is in line with theoretical models of MNEs which perceive MNEs as a self selected set of the best firms in any country (?). Secondly it confirms and qualifies an earlier study by Doms and Jensen (Doms and Jensen, 1998) for the US which shows a similar ranking for MNEs from different countries. However, in their case it could not be ruled out that the leadership of US multinationals was simply the consequence of a home advantage. Our results also have implications for economic policy in the UK where according to a widely held view incentives for foreign MNEs to locate in Britain are one potential instrument to increase aggregate productivity performance.

In the second part of our paper we exploit the longitudinal dimension of our data to look at three hypotheses regarding the nature of the MNE advantages. Firstly, is the superior performance of MNE plants driven by specific firm level assets - such as managerial skills, patents, branding and production processes - which MNEs can transfer to any of their subsidiaries (Markusen 1995 and Dunning 1981)? Secondly, are MNEs simply better at cherry-picking the best plants in the host country? Thirdly, do plants owned by British firms that start investing abroad experience productivity improvements as a direct consequence of FDI, because of, firm-level scale economies, technology sourcing from abroad or other learning effects? We find evidence confirming that the MNE advantage can be attributed to both MNEs having higher firm fixed effects and MNEs owning plants with better plant fixed effects. Regarding superiority of US firms over all other MNEs our evidence suggests that it is entirely driven by a particular ability of US firms to takeover the best British plants rather than improving the productivity of acquired plants any more than other MNEs do. Finally, our data does not find any robust evidence for an ex-post productivity increase in domestic plants of British firms that start investing abroad. This might be due to the short time series available to us.

An immediate question arising from our research, which might be the focus of future 
research, is as follows: why are US firms better than all other MNEs at obtaining the best plants? There are several possible explanations. One hypothesis is that managers of US MNEs pursue more aggressive takeover strategies and have specific skills that make them more successful in this activity. A second explanation is related to the particular time period considered. Indeed, in the second half of the 1990s, the US Stock market experienced a boom with spectacular equity prices increases. During that period, the S\&P500, the Dow Jones Industrial and the Nasdaq Composite indexes more than doubled. US MNEs, overvalued in the US stock market, and thus with access to low cost capital, might have found it more profitable to use this capital to target firms abroad (e.g. in the UK) not affected by the same stock market bubble, rather than in the home country ${ }^{64}$. With the data at hand, we cannot thoroughly investigate these hypotheses, but this is an area of research that deserves further exploration.

\section{References}

Abowd, J. M., Creecy, R. H., and Kramarz, F. (2002). Computing person and firm effects using linked longitudinal employer-employee data. mimeo.

Arellano, M. and Bond, S. R. (1991). Some tests of specification for panel data: Monte carlo evidence and an application to employment equations. Review of Economic Studies, 58:277-297.

Baily, M. N., Hulten, C., and Campbell, D. (1992). Productivity dynamics in manufacturing plants. Brookings Papers: Microeconomics, pages 187-267.

Baker, M., Foley, C. F., and Wurgler, J. (2004). The stock market and investment: Evidence from FDI flows. NBER Working Paper, 10559.

Blundell, R. and Bond, S. (1998). Initial conditions and moment restrictions in dynamic panel data models. Journal of Econometrics, 87:115-143.

Branstetter, L. (2001). Are knowledge spillovers international or intranational in scope? microeconometric evidence from the United States and Japan. Journal of International Economics, 53:53-79.

\footnotetext{
${ }^{64}$ This is the 'cheap capital' view of FDI (Baker et al., 2004)
} 
Conyon, M., Girma, S., Thompson, S., and Wright, P. (2002). The impact of foreign acquisition on wages and productivity in the United Kingdom. Journal of Industrial Economics, 50(1):85-102.

Criscuolo, C., Haskel, J., and Martin, R. (2003). Building the evidence base for productivity policy using business data linking. Economic Trends, 600:39-51.

Criscuolo, C. and Martin, R. (2003). Using the Annual Inquiry into Foreign Direct Investment to create a multinational identifier in the ARD. Ceriba data guide.

Davies, S. W. and Lyons, B. R. (1991). Characterising relative performance: the productivity advantage of foreign owned firms in theUK. Oxford Economic Papers, 43:584-595.

Dixit, A. K. and Stiglitz, J. E. (1977). Monopolistic competition and optimum product diversity. American Economic Review, 67:297-308.

Doms, M. E. and Jensen, J. B. (1998). Comparing wages, skills and productivity between domestically and foreign-owned manufacturing establishments in the United States. In Robert E. Baldwin, R. E. L. and Richardson, J. D., editors, Geography and Ownership as bases for economic accounting, pages 235-258. University of Chicago.

Dunning, J. H. (1981). International Production and the Multinational Enterprise. George Allen and Unwin.

Foster, L., Haltiwanger, J. C., and Syverson, C. (2003). Reallocation, firm turnover, and efficiency: Selection on productivity or profitability? working paper.

Griffith, R. (1999). Using the ARD establishment level data to look at foreign ownership and productivity in the UK. Economic Journal, 109:F416-F442.

Griffith, R. and Simpson, H. (2001). Characteristics of foreign owned firms in British manufacturing. IFS Working Paper.

Griliches, Z. and Mairesse, J. (1995). Production functions: The search for identification. NBER Working Paper, (5067).

Harris, R. (1999). Efficiency in UK manufacturing 1974-1994. mimeo. 
Helpman, E. (1984). A simple theory of international trade with multinational corporations. Journal of Political Economy, 92:451477.

Katayama, H., Lu, S., and Tybout, J. (2003). Why plant-level productivity studies are often misleading, and an alternative approach to interference. NBER Working Paper, (9617).

Keller, W. (2004). International technology diffusion. Journal of Economic Literature. forthcoming.

Klette, T. J. (1999). Market power, scale economies and productivity: estimates from a panel of establishment data. Journal of Industrial Economics, XLVII(4):451-476.

Klette, T. J. and Griliches, Z. (1996). The inconsistency of common scale estimators when output prices are unobserved and endogenous. Journal of Applied Econometrics, 11:343-361.

Levinsohn, J. and Petrin, A. (2000). Estimating production functions using inputs to control for unobservables. NBER Working Paper, (7819).

Lipsey, R. E. and Sjoholm, F. (2002). Foreign firms and Indonesian manufacturing wages: An analysis with panel data. NBER Working Paper, (9417).

Markusen, J. R. (1995). The boundaries of multinational enterprise and the theory of international trade. Journal of Economic Perspectives, 9(2):169-186.

Martin, R. (2002). Building the capital stock. CeRiBA mimeo.

Martin, R. (2003). Computing the true spread. Ceriba mimeo, http://www.qmul.ac.uk/ ugte153/CERIBA/publications/prof_spread004.pdf.

Melitz, M. J. (2000). Estimating firm-level productivity in differentiated product industries. working paper.

Office for National Statistics (2002). Foreign Direct Investment 2000 - Business Monitor MA4. HMSO, London.

Olley, S. and Pakes, A. (1996). The dynamics of productivity in the telecomunications equipment industry. Econometrica, 64:1263-97. 
O’Mahony, M. and de Boer, W. (2002). Britain's relative productivity performance: updates to 1999. Final report to DTI/HM Treasury/ONS, NIESR.

Oulton, N. (1997). The ABI Respondents Database: A new resource for industrial economics research. Economic Trends, 528:46-57.

Oulton, N. (2000). Why do foreign-owned firms in the UK have higher labour productivity? Bank of England.

Syverson, C. (2004). Market structure and productivity: A concrete example. Journal of Political Economy, 112(6):1181-1222. 


\section{A Variable Definitions}

- Capital stock: capital stock was calculated using a perpetual inventory method (PIM). For a more detailed description of the method adopted we refer to Martin (2002)

- Deflators: to deflate output measures (gross output and value added) we use producer price indices at the 4-digit SIC92 industry level. To deflate intermediates, we use material price deflators at the 2-digit SIC92 industry level. The base year is 1995. Capital stock is deflated using investment deflators with base year 1995; for years pre-1995 these are implicitly derived from nominal and real sectoral ONS historical investment series. From 1995 onwards I use the publicly available MM17 series.

- Foreign plants are plants owned by foreign owned enterprise groups.

- Country groups:

EUnorth includes plants owned by Austria, Belgium, Denmark, Finland, Luxembourg, Sweden and Republic of Ireland.

EUsouth includes plants owned by Italy, Spain and Canary Islands, Portugal and Greece.

Tax includes plants owned by British Virgin Islands, Channel Islands, Isle of Man, Liechtenstein, Antigua and Barbuda, Cyprus and US Virgin Islands.

otherEurope includes plants owned by Norway and Switzerland.

otherOECD includes plants owned by Australia, Canada, Czech Republic, Iceland, Mexico, Poland, South Korea and Turkey.

other is a residual category that includes plants owned by the rest of the world and plants which are foreign owned but whose nationality is unknown.

- Weights are calculated using the register employment information on the basis of 4 digit sector, region and employment cells. For each cell $i$ the weight is calculated as $\frac{\text { Number of plants in register in cell i }}{\text { Number of selected plants cell } \mathrm{i}}$. 


\section{B The monotone relationship between profits and shocks}

Start by noting that given our assumption of a homogenous production function (equation 7) we can write the cost minimization problem as:

$$
\breve{C}\left(\breve{K}_{i t}, \mathbf{w}_{V i t}\right)=\min _{\breve{\mathbf{X}}_{V i t}} \sum_{z \neq K} w_{z i t} \breve{X}_{z i t} \text { s.t. } 1=f\left(\breve{K}_{i t}, \breve{\mathbf{X}}_{V i t}\right)
$$

where $w_{z i t}$ represents the cost of factor $z$ and $\breve{K}_{i t}=\frac{K_{i t}}{Q_{i t}}$ with $\breve{Q}_{i t}=\left(\frac{Q_{i t}}{A_{i t}}\right)^{\frac{1}{\gamma}} \cdot \breve{\mathbf{X}}_{V i t}$ collects the same transformation for all variable production factors in a vector. Total cost become in terms of Equation 29

$$
C_{i t}=\breve{C}_{i t} \breve{Q}_{i t}
$$

Next consider the profit function.

$$
\Pi_{i t}\left(K_{i t}, \lambda_{i t}, a_{i t}, \mathbf{w}_{i t}\right)=R_{i t}-C_{i t}
$$

Given the demand function 4 and the cost function 30 we can write it as

$$
\Pi_{i t}\left(K_{i t}, \lambda_{i t}, a_{i t}, \mathbf{w}_{i t}\right)=\left(\frac{\Lambda_{i t} R_{t}}{P_{t}}\right)^{\frac{1}{\eta}} P_{t} Q^{1-\frac{1}{\eta}}-\breve{C}_{i t} \breve{Q}_{i t}
$$

Note that the firm's profit maximization first order condition is

$$
\left(1-\frac{1}{\eta}\right) \frac{R_{i t}}{Q_{i t}}=\frac{1}{\gamma} z\left(\breve{Q}_{i t}, \breve{K}_{i t}\right) \frac{\breve{Q}_{i t}}{Q_{i t}}
$$

where

$$
z\left(\breve{Q}_{i t}, \breve{K}_{i t}\right)=\frac{\partial \breve{C}_{i t}}{\partial \breve{Q}_{i t}} \breve{Q}_{i t}+\breve{C}_{i t}
$$

Finally, note that the derivatives of profit with respect to changes in $\lambda_{i t}$ and $a_{i t}$ are

$$
\frac{\partial \prod_{i t}}{\partial \lambda_{i t}}=\mu^{-1} R_{i t}
$$

and

$$
\frac{\partial \Pi_{i t}}{\partial a_{i t}}=z\left(\breve{Q}_{i t}, \breve{K}_{i t}\right) \frac{1}{\gamma}\left(\frac{Q_{i t}}{A_{i} t}\right)^{\frac{1}{\gamma}}=\mu^{-1} R_{i t}
$$


where the last equality follows from the first order condition $32^{65}$ and

$$
\mu=\left(1-\frac{1}{\eta}\right)^{-1}
$$

As a consequence of all these results we get for the total differential of profits

$$
d \Pi_{i t}=R_{i t} \frac{1}{\mu}\left(d \lambda_{i t}+d a_{i t}\right)=R_{i t} d \omega_{i t}
$$

which establishes that there is a positive relationship between profits and composite shock index $\omega_{i t}$.

${ }^{65}$ This is an application of the envelope theorem 


\section{Testing if $\mu$ is constant}

In this section, we describe a simple test of the hypothesis that $\mu$ is uniform within each 4 digit sector based on over-identifying restrictions. As expected, the null hypothesis is rejected in the majority of sectors. Column 3 of table ?? shows estimates of equation 20 on a restricted sample of plants in sectors where the null hypothesis of uniform $\mu$ cannot be rejected to check the robustness of our results. Our test works as follows: if we want to allow for a more general market structure then the coefficient of capital in Equation 18 is not constant but depends on the quality parameter of the firm, $\lambda_{i t} .{ }^{66}$

$$
r_{i t}-v i_{i t}=\beta_{i t-1}^{K} k_{i t}+g\left(k_{i t-1}, \Pi_{i t-1}\right)+\nu_{i t}
$$

where $\beta_{i t-1}^{K}=\frac{\gamma}{\mu}\left(\lambda_{i t-1}\right)$. ${ }^{67}$ If we nevertheless used a specification with constant $\beta^{K}$ we are faced with the following situation:

$$
r_{i t}-v i_{i t}=\beta^{K} k_{i t}+g\left(k_{i t-1}, \Pi_{i t-1}\right)+\nu_{i t}+\left(\beta_{i t}^{K}-\beta^{K}\right) k_{i t}
$$

where $\beta^{K}$ represents the constant capital coefficient we estimate. Equation 37 shows that there is unaccounted for heterogeneity which is correlated with the explanatory variables, thus an estimator based on zero correlation conditions between $k_{i t}, \Pi_{i t-1}$, etc. and the error term breaks down. Equation 37 is the alternative specification to the null hypothesisof a constant $\beta_{K}$. Thus it can help us find restrictions which allow us to test our hypothesis. We already mentioned the first set of these restrictions: zero correlation between $\check{\varepsilon}_{i t}=r_{i t}-v i_{i t}-\beta^{K} k_{i t}-g\left(k_{i t-1}, \Pi_{i t-1}\right)$ and the explanatory variables in 37 :

$$
E\left\{\check{\varepsilon}_{i t} X_{i t}\right\}=0
$$

where $X_{i t} \in\left\{k_{i t}, k_{i t-1}, \Pi_{i t-1}\right\}$. An additional instrument would be the interaction between current capital stocks and last periods demand shock, $k_{i t} \cdot \lambda_{i t-1}$. The problem with this is of course that $\lambda_{i t-1}$ is not observed. Note however that since $\lambda_{i t}$ is a component of $\omega_{i t}$ and although $\omega_{i t}$ is not observed we have a way of controlling for it: we approximate it by

\footnotetext{
${ }^{66}$ For simplicity we make the formal argument in terms of log levels and not deviations from log values of the median plant as in section 5.3. The argument can be made similarly in both cases.

${ }^{67}$ Note that in order to use our test we implicitly need to assume that there is a certain sluggishness in price setting: markups depend on last period's realization of the $\lambda$-shock, as we describe below.
} 
a polynomial in $\Pi_{i t}$ and $k_{i t}$. This implies that we can derive additional zero correlation conditions for the interaction of $k_{i t}$ with all lagged polynomial terms, thus under the null $\check{\varepsilon}_{i t}$ will not be correlated with terms such as $k_{i t} \cdot k_{i t-1} \cdot \Pi_{i t-1}$, etc. Note here, that it is crucial to make the assumption about sluggish prices. Because there would always be a correlation between $\nu_{i t}$ and $\omega_{i t}$ we could not make a similar argument starting from a zero correlation condition between $k_{i t} \cdot \lambda_{i t}$ and $\check{\varepsilon}_{i t}$. Finally note that, because of the presence of $k_{i t}$ in $\check{\varepsilon}_{i t}$, under the alternative hypothesis (37), all these zero correlation conditions break down and they are thus indeed a means to test our hypothesis.

We implement the test as a Sargan-Test where we use the restrictions in 38 to exactly identify all required parameters and then test the zero correlation of the restrictions from the polynomial interactions as a $\chi^{2}$-distributed statistic. 
Table 7: Statistics on double fixed effects groups

(1)

\begin{tabular}{rccc} 
& obs & plants & firm \\
\hline $\min$ & 2 & 1 & 1 \\
$\max$ & 634 & 201 & 55 \\
median & 3 & 1 & 1 \\
\hline \hline groups & 6754 & & \\
obs & 28338 & & \\
\hline
\end{tabular}

Notes: The first panel reports summary statistics for the double fixed effects groups (DFG) in our sample. Column 1 row 1 shows that the smallest DFG consists of 2 observations, the largest of 634 and the median group of 3 observations. Columns 3 and 4 report the same statistics for the numbers of plants and firms.

\section{A double fixed effects approach}

We suggested that Equation 22 could also be estimated using a double fixed effects methodology. This section discusses how this could be done and the problems it raises.

Firm and plant effects can be identified separately to the extent that plants move between firms. Abowd et al. (2002) have laid out in detail which firm and plant effects we can hope to identify: ${ }^{68}$ They define sets of 'double fixed effect groups' (DFG). A DF group $D F G_{g}$ is defined as the set of all firms and plants which interact over the sample period. A firm and a plant interact simply if the plant is owned by the firm. Two plants interact if they are both owned by the same firm at some but not necessarily the same point in time. Two firms interact if they own the same plant at different points in time.

Abowd et al. show that for each plant and each firm in a DFG one can identify a fixed effect which is informative about its productivity relative to the group average, where the group average includes the fixed effect of an omitted reference firm, $\mu_{R}$, and an omitted reference plant $\alpha_{r}$. Thus, any estimated fixed effect has to be interpreted as relative to the omitted plant and firm.

Table 7 reports some statistics on these groups. Consider first the second panel which reports that there are in total 6754 such groups in our dataset. Also note that the number of observations has now reduced because we can only use observations from plants we observe at least twice. Panel 1 reports various statistics on these 6,754 groups. We see that the majority of groups is rather small. Both the median number of plants and firms

\footnotetext{
${ }^{68}$ Abowd et al. work with matched employer-employee panels but their results apply to our problem immediately once plants take on the role of employees and firms the role of employers.
} 
Table 8: Double fixed effects regression results

\begin{tabular}{lcc} 
& $(1)$ & $(2)$ \\
\hline US & -0.031 & 0.039 \\
& $(0.013)^{* *}$ & $(0.024)^{*}$ \\
MNE & 0.002 & 0.020 \\
& $(0.018)$ & $(0.018)$ \\
FOR & 0.026 & 0.028 \\
& $(0.018)$ & $(0.025)$ \\
green GB non MNE & & 0.000 \\
& & $(0.021)$ \\
green US & & 0.030 \\
& & $(0.054)$ \\
green FOR & & 0.037 \\
& & $(0.063)$ \\
green MNE & & -0.001 \\
& & $(0.037)$ \\
obs & 2842 & 2865
\end{tabular}

Notes: Bootstrapped standard errors in parentheses. Coefficients and standard errors are from the third-stage of the double-fixed effects model. In column 1 the dependent variable is firm fixed effects estimated in the second-stage. ever US firm is 1 for all US firms. ever MNE firm is 1 for all MNE firms. ever FOR firm is 1 for non US foreign firms. In Column 2 the dependent variable is the plant fixed effects estimated in the second-stage ever MNE plant is 1 for all plants that have ever been owned by a MNE over the course of the sample period. Similarly for the ever US and ever other foreign dummies. The green dummies take value one for all plants that are established during the course of the sample period (1996-2000), green GB non MNE is one for plants owned by domestic firms when established. green MNE is one for plants owned by MNE firms when established. green US (green FOR) is one for plants owned by US (other foreign) firms when established.

${ }^{*}$ significantly different from zero at the 10 percent level. ${ }^{* *}$ significantly different from zero at the 5 percent level. ${ }^{* * *}$ significantly different from zero at the 1 percent level.

(row 3 in columns 2 and 3 ) is 1 one which means that our dataset consists mainly of firms that own one plant which is never sold. For these there is no chance of separating firm and plant effects. Our sample thus reduces to those groups which consist of at least 2 plants or firms. This corresponds to about one third of our original sample.

After establishing how many fixed effects can effectively be identified the double fixed effects problem is in principle nothing else but a regression on dummies for each plant and firm whose fixed effect can be identified. However, this runs into computational problems because of the sheer size of the matrices that are to be inverted. Abowd et al. apply some advanced linear algebra techniques to get round this problem. However, since all coefficients' estimates are relative to a group, neither efficiency of consistency is lost if estimates are obtained separately for each group. In our case the largest group consists of 55 firms and 201 plants. This is still in the range feasible for a normal dummy variable regression, which is our strategy. In each group we can then estimate the fixed effects of each plant and firm except for one reference plant and firm:

$$
\alpha_{i} \widehat{-\alpha_{r}-} \mu_{R} \quad \text { and } \quad \mu_{J} \widehat{-\alpha_{r}}-\mu_{R}
$$


where $\alpha_{r}$ is the reference plant and $\mu_{R}$ the reference firm.

To examine the existence of MNE firm and plant effects as discussed in Section 6 we regress these estimated fixed effects on MNE plant and firm dummies; i.e. for the firm effect:

$$
\mu_{J} \widehat{-\alpha_{r}}-\mu_{R}=\beta_{M N E_{F i r m}^{e v e r}} M N E_{J(i, t)}^{e v e r}+\varepsilon_{i t}
$$

Can we hope that $\beta_{M N E_{\text {Firm }}^{e v e r}}$ provides a consistent estimator of

$$
E\left\{\mu_{J} \mid M N E_{J(i, t)}^{e v e r}=1\right\}
$$

Only if we can assume that there is no systematic correlation between $\mu_{J}+\alpha_{i}$ and $M N E_{J(i, t)}^{e v e r}$. However, this is unlikely because multinational firms are more likely to interact with other multinational firms or with domestic firms which have higher productivity so that $E\left\{\mu_{J} \mid 1\right\}>E\left\{\mu_{J} \mid 0\right\}$. This would introduce a downward bias in our estimate of

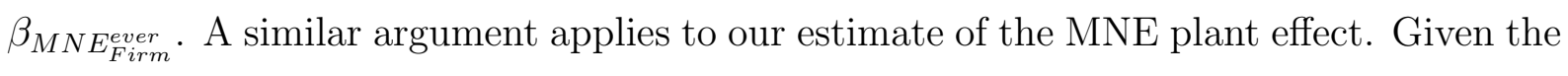
downward bias we expect that regressions of 39 and the equivalent plant equation lead to lower MNE firm and MNE plant estimates than the results found in Section 6.

Table 8 shows estimates of equation 39 in column 1 and the equivalent plant level equation in Column 2. All point estimates are lower than the comparable estimates in Section 6 and most effects are found to be non significant. Only the US plant effect is still significant at the 10 percent level (column 2, row 1), whereas The US firm effect estimate is now negative and significant at the 5 percent level. 


\section{CENTRE FOR ECONOMIC PERFORMANCE Recent Discussion Papers}

671 Roberto Torrini

670 Silvia Ardagna Francesco Caselli Timothy Lane

669 Alejandro Cuñat Marco Maffezzoli

668 Francesco Caselli Silvana Tenreyro

667 Francesco Caselli

666 Gianluca Benigno Pierpaolo Benigno

665 Olmo Silva

664 Maarten Goos

663 Christopher A. Pissarides Giovanna Vallanti

662 Philip R. Lane Gian Maria Milesi-Ferretti

661 Alex Bryson Lorenzo Cappellari Claudio Lucifora

660 David Marsden Richard Belfield

659 Rachel Griffith Rupert Harrison John Van Reenen
Profit Share and Returns on Capital Stock in Italy: the Role of Privatisations Behind the Rise of the 1990s

Fiscal Discipline and the Cost of Public Debt Service: Some Estimates for OECD Countries

Can Comparative Advantage Explain the Growth of US Trade?

Is Poland the Next Spain?

Accounting for Cross-Country Income Differences

Designing Target Rules for International Monetary Policy Cooperation

Entrepreneurship: Can the Jack-of-All-Trades Attitude be Acquired?

Sinking the Blues: the Impact of Shop Closing Hours on Labor and Product Markets

Productivity Growth and Employment: Theory and Panel Estimates

Financial Globalization and Exchange Rates

Do Job Security Guarantees Work?

Unions, Performance-Related Pay and Procedural Justice: the Case of Classroom Teachers

How Special is the Special Relationship? Using the Impact of R\&D Spillovers on UK Firms As a Test of Technology Sourcing 
658 Douglas Kruse

Richard B. Freeman

Joseph Blasi

Robert Buchele

Adria Scharf

Loren Rodgers

Chris Mackin

657 Christopher Crowe

656 James Banks

Richard Disney

Alan Duncan

John Van Reenen

655 Eran Yashiv

654 Hilary Steedman

Sheila Stoney

653 Ralf Martin

652 Jörn-Steffen Pischke

651 Anthony J. Venables

650 John Van Reenen

649 Rachel Griffith

Stephen Redding

Helen Simpson

648 Fredrik Andersson

Simon Burgess

Julia I. Lane
Motivating Employee Owners in ESOP Firms:

Human Resource Policies and Company Performance
Inflation, Inequality and Social Conflict

The Internationalisation of Public Welfare Policy
The Self Selection of Migrant Workers Revisited

Disengagement 14-16: Context and Evidence

Globalisation, ICT and the Nitty Gritty of Plant Level Datasets

Labor Market Institutions, Wages and Investment

Evaluating Urban Transport Improvements: Cost Benefit Analysis in the Presence of Agglomeration and Income Taxation

Is There a Market for Work Group Servers?

Evaluating Market Level Demand Elasticities Using Micro and Macro Models

Foreign Ownership and Productivity: New Evidence from the Service Sector and the R\&D Lab

Cities, Matching and the Productivity Gains of Agglomeration

\section{The Centre for Economic Performance Publications Unit Tel 02079557673 Fax $02079557595 \quad$ Email info@cep.lse.ac.uk Web site http://cep.Ise.ac.uk}

